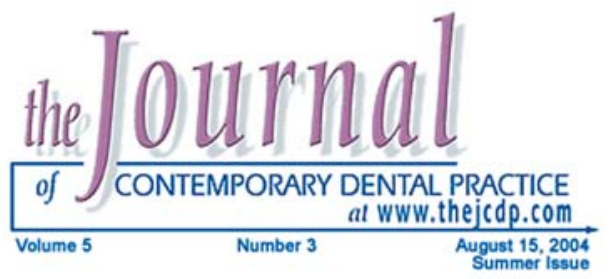

\title{
Evaluation of Changes in the Mandibular Angular Cortex Using Panoramic Images
}

Fatemeh Ezoddini Ardakani, DDS, MS; Nasim Niafar, DDS
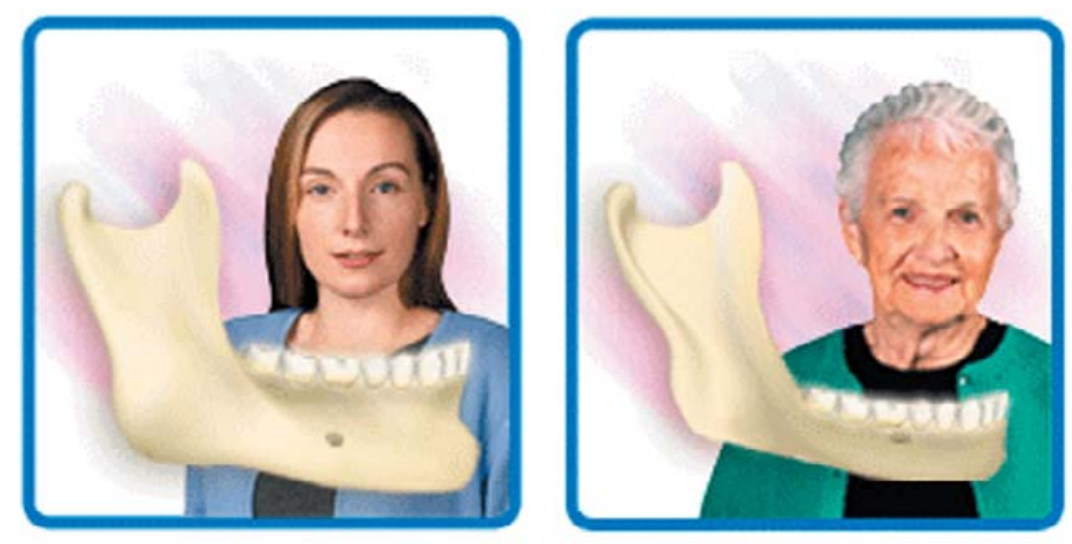

\begin{abstract}
The mandible like other bones of the body has a series of anatomical landmarks that can serve as radiographic indicators. Using these indicators it is possible to evaluate changes in bone with respect to its quantity or quality by different methods of taking images. Osteoporosis is a significant problem of the elderly, especially postmenopausal women. The aim of this study was to determine the thickness of the mandiublar angular cortex on the right and left sides of women as well as bone resorption in different age groups using panoramic radiography. One hundred female patients were selected from applicants for panoramic radiological services who did not have a history of systemic bone disease, hysterectomy, or taking hormonal supplements.

Using a questionnaire, the selected subjects were asked questions about their education, job, marital status, number of pregnancies, age, menopausal status, and history of backaches. After statistical calculation it became clear an increase in age will increase bone resorption, and this process is related to a decrease in the sexual hormones of women. Higher bone resorption was detected in women with a higher number of pregnancies. Also, the higher educated the patient, the less bone resorption. Women with a background of backaches had more bone resorption to those who did not have this backache background. Finally, it was recognized that it would be possible to clear the quality dimension of the process of mandibular bone resorption.
\end{abstract}

Keywords: Panoramic radiography, mandibular angular cortex, osteoporosis

Citation: Ardakani FE, Niafar N. Evaluation of Changes in the Mandibular Angular Cortex Using Panoramic Images. J Contemp Dent Pract 2004 August;(5)3:001-015.

(c) Seer Publishing 


\section{Introduction}

The mandible, like other bones of the body, has a series of anatomic indicators. Using these indicators it is possible to assess bone changes in terms of quantity or quality by using different radiographic strategies.

In order to assess the loss of bone integrity it is essential to recognize normal anatomical landmarks if they are to be used as indicators of bone changes. Key mandibular anatomical landmarks include: symphysis, genial tubercle, mental ridge, nutrient canals, mandibular canal, mylohyoid ridge, submandibular gland fossa, external oblique ridge, and the mandibular inferior ridge.

\section{Inferior Cortex of the Mandible}

The inferior bony cortex of the mandible is dense, wide, and appears as a very radiopaque strip of bone along the inferior border of the mandible.,

Using mandibular anatomic indicators on panoramic radiography can be useful in the evaluation of bone resorption in different age groups of women to determine the existence of osteoporosis. One of the most useful bony landmarks to use as an indicator for the analysis of bone metabolism is the mandibular angular cortex. The cortex layer of the angle of the mandible is not visible before the age of 15 (Figure 1).

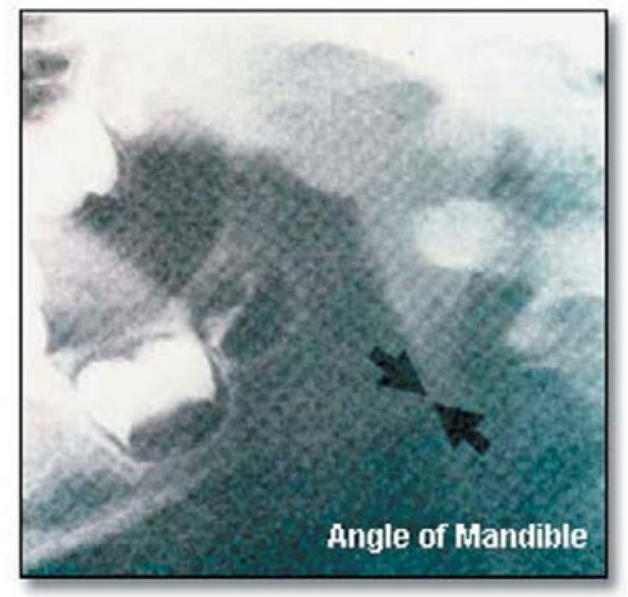

Figure 1. Mandibular angle before growth.

After age 15, the thickness of the cortex is almost fixed except in women. In women it will become thinner over time (Figures 2 and 3). ${ }^{1,4}$

In this study cortical changes of the mandibular angular area were observed in women who were more than 20 years old. Correlations with other
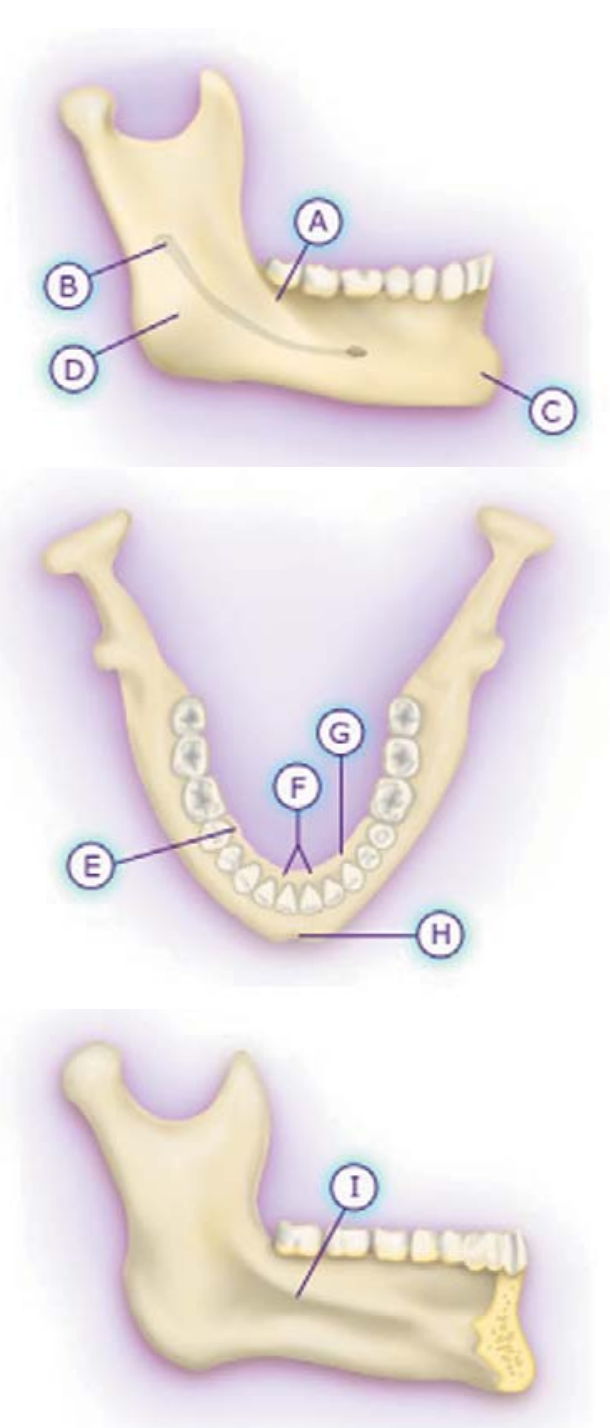

Key:
A. External Oblique Ridge
B. Mandibular Canal
C. Mental Ridge
D. Nutrient Canals
E. Submandibule Inferior Fossa
F. Genial Tubercules
G. Mental Ridge
H. Chin Symphysis
I. Mylohyoid Ridge

factors like marital status, number of pregnancies, occupation, education, age, menopausal status, and backache were explored.

Osteoporosis is the most common metabolic bone disease. It is a generalized rarefaction of bone. This disease is commonly found in the elderly, especially in menopausal women. There are several causes of osteoporosis including Cushing's syndrome, drug-induced atrophy, malnutrition, tirotoxicos, and post-menopause. 


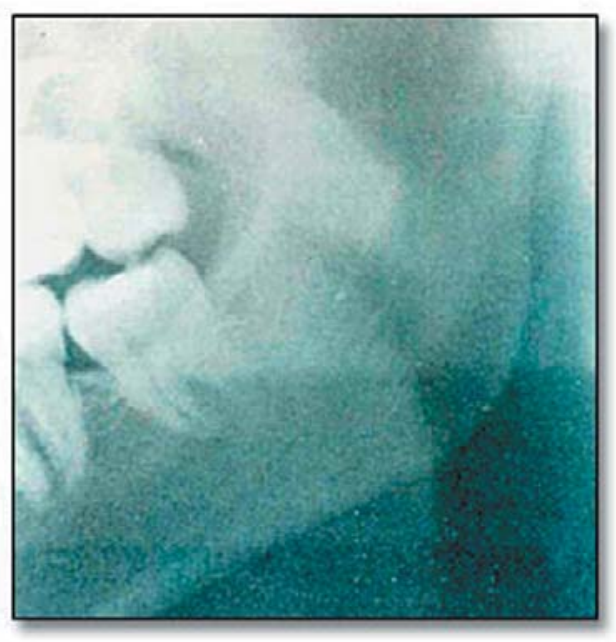

Figure 2. Thick cortical layer in the mandibular angle in a 34-year old female.

Osteoporosis can affect all bones of the body. ${ }^{5,6}$ Osteoporosis is the deficiency of bone texture in a unit of bone volume. Osteoporosis causes a decrease in the physical density of bone. Histologically, other characteristics of bone appear normal. Bone mass naturally increases from embryonic states to ages 35 and 40 years. At this time, a gradual decrease in mass begins. ${ }^{3}$ The percent of decrease for women is about $8 \%$ for every decade and $3 \%$ for men. This bone resorption is especially visible in cortical bone and continues until death. Men experience $50 \%$ cortical bone resorption at 80 years of age, while women experience $50 \%$ at 70 years and $100 \%$ at the age of 90 .

Through the process of osteoporosis, trabecular bone is affected sooner than dense cortical bone. ${ }^{2}$ Trabecular bone loss in young people in both sexes is initiated but is more profound in females. Around the period of menopause rapid reduction in cortical bone is seen with an increase in age. ${ }^{6}$

\section{Clinical View}

Most osteoporosis patients lack clinical symptoms. However, in advanced cases severe pain during body movement is a common symptom. It is common for the elderly to experience backaches due to the presence of osteoporosis. This disease has a tendency to affect the center portion of the vertical-axial skeleton.

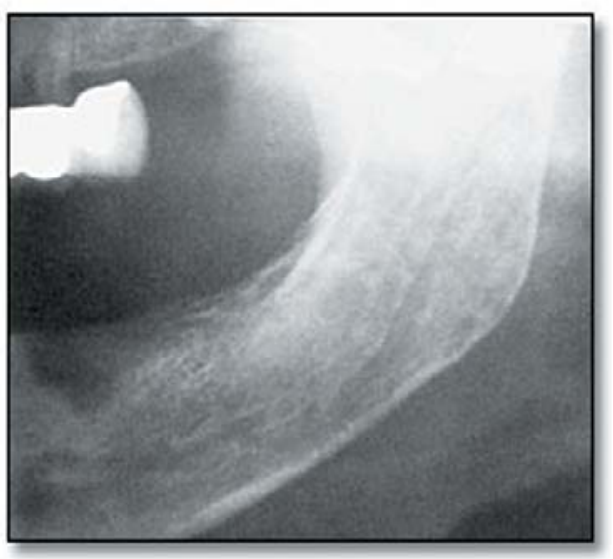

Figure 3. A very thin cortical layer in the mandibular angle in a 67-year old female.

As a result, the spinal column, long bones of the pelvis, and skull are common sites for loss of bone mass. Patients suffering from osteoporosis gradually become shorter and their spinal columns become extremely curved. ${ }^{7}$

\section{Radiographic View}

For diagnosing osteoporosis by radiography, at least $30 \%$ of bone calcium should be decreased: usually the disease will partly develop before making radiographic view. The most frequently observed symptoms of osteoporosis shown on a radiograph are: the reduction of overall bone density,

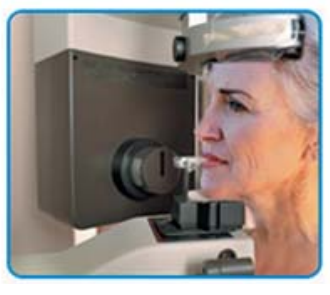
thinner and less dense cortical bone, and disruption of normal trabecular view. In some cases such as in Cushing's syndrome and patients under long-term cortisone therapy the mandible is significantly affected. As osteoporosis becomes more advanced, the most visible radiographic change is the thinning of cortical bone. Therefore, the clinician will be able to diagnose osteoporosis in older patients by assessing the reduction of density (radiopacity) and the thinness of the mandibular lower cortex as compared to the mandible of teenagers and young adults.

Diagnosing changes in spongy bone is harder than diagnosing cortical changes in panoramic radiography. Osteoporosis does not change the ladder-like appearance of the trabeculae which are seen in normal bones. ${ }^{3}$

In a study by Bras et al. ${ }^{4}$ the thickness of the mandibular angular cortex in panoramic radiography was compared in males and females in order to 
develop a useful parameter in diagnosing metabolic bone disease in menopausal women. Another study by Kribbs et al. ${ }^{8}$ evaluated the thickness of the mandibular cortex in the gonion area in both normal and osteoporotic women. The later group was found to have a thinner cortical bone.

Osteoporosis studies can be grouped with respect to etiological factors.

\section{Menopausal Osteoporosis and Senile Osteoporosis}

Osteoporosis type 1 or menopausal osteoporosis generally starts about 10 years before menopause. Its maximum ansidence is in the $7^{\text {th }}$ decade of life. Northern European and Asian women are at greater risk, while blacks are less vulnerable to osteoporosis probably due to larger bone structure and muscle mass resulting in a decrease in bone turn over. ${ }^{5}$ Women experience an increase in bone resorption associated with menopause. $^{2}$ Senile osteoporosis could result from other factors such as reduction of calcium absorption due to a decrease in vitamin $\mathrm{D}$ metabolism common in old age; a decrease in muscle activity decreases blood flow. This coupled with a decrease in blood pressure puts bone in a hypoxic status creating a favorable condition for bone resorption (Figure 4). ${ }^{1}$

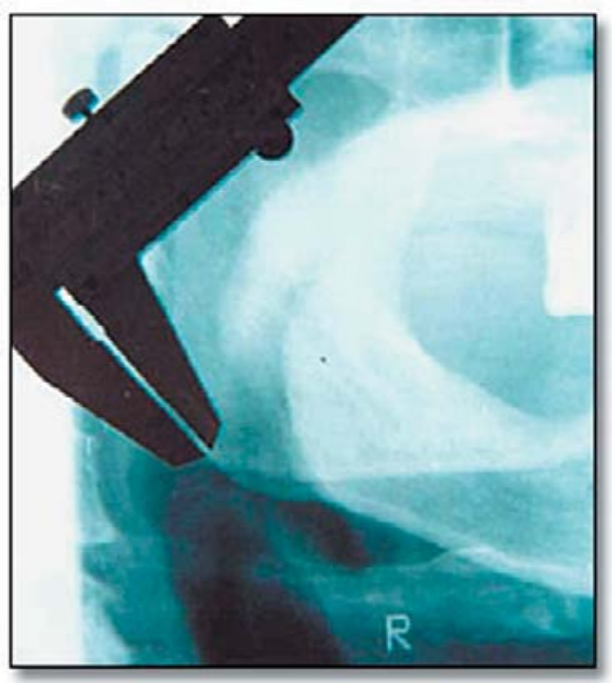

Figure 4. Measurement of the mandibular angular cortex from a radiographic image.

Jeffecoat et al. ${ }^{9}$ investigated systematic osteoporosis and the resorption of bone in the jaws. With an increase in age they noted a decrease in bone mass and concluded there is an increasing risk of bone resorption in the orofacial region and other parts of the body. Birkenfeld et al..$^{10}$ investigated alveolar bone resorption and its relationship to menopause. Osteoporotic changes of the alveolar processes of the maxilla and mandible has a direct effect on stability of teeth. A result of their studies show there is a direct relationship between bone mass and systematic osteoporosis. They found estrogen therapy as a useful factor in the alveolar process of mandibular and maxillar bones. Using estrogen during the menopause period probably helped with the stability of teeth.

\section{Osteoporosis in Cushing Syndrome}

Cushing syndrome is caused by an increase in the production of glucocorticosterioids by the adrenal gland. Osteoporosis is present in $64 \%$ of women and $75 \%$ of men who are suffering from Cushing syndrome. The pelvis, ribs, vertebrae, long bones, and skull are affected more than other bones. In advanced stages the maxilla and mandible also suffer. Lamina dura disappears or becomes thin. Once the function of the adrenal glands is controlled, bone density in young people returns to normal. Unfortunately this is not the case in adults. ${ }^{1}$

\section{Osteoporosis Due to Drug Consumption}

Taking glucocorticosteroids for a long time can cause a Cushing-like status resulting in osteoporosis. Prescribing simultaneous doses of androgen, estrogen, calcitonin, and fluorides cannot counteract the effect of the corticosteroids. ${ }^{1}$

\section{Osteoporosis and Malnutrition}

There is some evidence that consuming an insufficient amount of calcium during one's lifetime can maximize bone loss which can result in an increase risk of fractures. ${ }^{1}$

\section{Osteoporosis and Lifestyle} The lack of body movement in sedentary individuals can contribute to an increase in bone resorption and a decrease in bone production. Exercise can decrease the percent of bone loss in menopausal women. ${ }^{5}$ Benson et al. ${ }^{11}$ introduced a new index of radiomorphometric assessment 
of mass bone called the Panoramic Mandibular Index (PMI). A high PMI means less bone resorption. Using this index they studied 353 subjects which revealed that black patients have a larger $\mathrm{PMI}$ average in comparison to Caucasians and South American Hispanics. There was a considerable decrease in average PMI with an increase in age of black women and South American Hispanic women. The PMI average in white men increases with age.

Devlin et al. ${ }^{12}$ used dental panoramic tomogram and densitometry as a method of evaluating the mandibular bone mineral content.

Kribbs et al. ${ }^{13}$ measured mandibular bone mass in menopausal osteoporosis women over a two year period. They investigated the role of an active form of vitamin D, "Dihydroxycholecaluciferol" 1.25, (1.25-DHCC), in osteoporosis cases and concluded diets containing high levels of calcium and vitamin $\mathrm{D}$ help to preserve mandibular bone.

\section{Material and Methods}

The project was conducted as a cross-sectional, descriptive study using random sampling.

One hundred randomly selected female patients who qualified were referred to the Oral Radiology Department of the Dental Faculty of Shahid Sadoughi University of Yazd (Iran) for panoramic radiographic services and were included in the study. Women who were under 20 years of age and had a history of bone systematic disease, taking drugs, or hysterectomy surgery were excluded from the study.

For statistical analysis, the t-test was used to determine the relationship of independent quantitative variants with the thickness of mandibular angular cortex. When quantitative variants were more than two cases, one way variance analysis was used. Regression analysis was used for investigating the relationship of quantitative variants with the thickness of the mandibular angular cortex.

A Plan Meca $2002^{\mathrm{TM}}$ machine, EC Proline ${ }^{\mathrm{TM}}$ (made in Finland) and Kodak panoramic film sensitive to green light was used to acquire panoramic radiographs that were prescribed for them in two clinics.

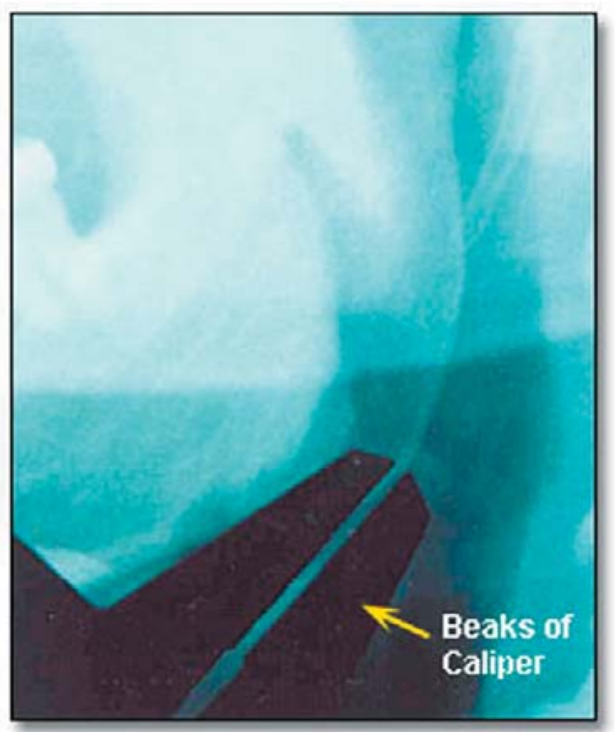

Figure 5. Measurement of the mandibular angular cortex from a radiographic image (left side).

Panoramic radiographs in both places were prepared by the same technician. The thickness of the mandibular angular cortex on both left and right sides of the panoramic radiographs were measured with a Vernier caliper. (Figure 5) This information along with other specifications of the patients was recorded in a patient questionnaire.

\section{Results}

The mean thickness of the mandibular angular cortex in 100 randomly selected female patients was $2.77 \pm 1.246 \mathrm{~mm}$. The studied variables were age, menopausal status, educational level, marital status, occupation, number of delivery, and the history of backaches.

From the total number of investigated cases, $28 \%$ were menopausal and $82 \%$ were pre menopausal. The age groups of the cases were as follows: $20-29$ years $33 \%$, 30-39 years $16 \%, 40-49$ years $28 \%, 50-59$ years $17 \%$, and $6 \%$ were over 60 years. Fourteen percent of the cases were single and the rest $(86 \%)$ were married.

Our results showed a statistically significant relationship between the thickness of the mandibular cortex and the patients' age ( $p$ value $=0.0001$ ) The relationship was as follows:

Thickness of Mandibular Cortex $=$ $5.8-(0.0078 \times$ age $)$. 
This means the older one gets the thickness of the mandibular cortex decreases, i.e., each year the thickness of the mandibular cortex will decrease $0.007 \mathrm{~mm}$ (Table 1).

In addition we found a statistically significant relationship between the thickness of the mandibular cortex and the patients' menopausal age $(p$ value $=0.0001)$. With the increase in the menopausal age, there is a decrease in the thickness of the mandibular cortex. The relationship was as follows:

\section{Thickness of Mandibular Cortex =} $6.61-(0.1010 \times$ menopausal age $)$

For every year the menopausal age increases, the thickness of the mandibular cortex will decrease $0.1 \mathrm{~mm}$ (Table 2).

Our results showed a statistically significant relationship between the thickness of the mandibular cortex and the number of births by a woman ( $p$ value $=0.0001$ ). The relationship was as follows:

\section{Thickness of Mandibular Cortex =}

$$
3.87-(0.359 \times \text { number of births })
$$

For each extra birth, there will be a $0.359 \mathrm{~mm}$ decrease in the thickness of the mandibular cortex (Table 3).

A statistically significant difference between the thickness of the mandibular cortex and the patients' menopausal status was found in our results as well ( $p$ value $=0.0001$ ). The mean thickness of the mandibular cortex was $1.83 \pm$ $1.811 \mathrm{~mm}$ in the menopausal women and $3.13 \pm$ $1.41 \mathrm{~mm}$ in the remainder. This shows nearly a two-fold decrease in the mean thickness of the mandibular cortex in the menopausal women (Table 4).

Twenty percent of the cases had backache history; the mean thickness of the mandibular cortex was $1.58 \pm 0.538 \mathrm{~mm}$ in these women and $3.08 \pm 1.38 \mathrm{~mm}$ in the women with no history of backache (Table 5). The difference between these two groups is statistically significant ( $p$ value $=0.0001)$.

The other significant finding in our results was the difference in the thickness of the mandibular cortex between married and single women (Figure 6). The mean thickness of the mandibular cortex in the married women was less than the thickness in the single women $(2.57 \pm 1.308 \mathrm{~mm}$ and $4.03 \pm 1.29 \mathrm{~mm}$, respectively).

The educational status of the studied women was the other factor important in the mean thickness of the mandibular cortex. The higher educated the woman, the higher the thickness of the mandibular cortex. This thickness was $2 \pm 1.07 \mathrm{~mm}$ in uneducated women, $1.92 \pm 0682 \mathrm{~mm}$ in the women who finished only primary school, $2.35 \pm$ $1.475 \mathrm{~mm}$ in the women who finished only secondary school, $2.96 \pm 0.837 \mathrm{~mm}$ in the women who finished high school, and $4.51 \pm 1.009 \mathrm{~mm}$ in the women with university degrees. These differences were statistically significant $(p$ value $=$ 0.0001) (Figure 7).

\section{Discussion}

Osteoporosis is a generalized rarefaction of bone resulting from a deficiency in bone matrix and a shortage of mineral. ${ }^{1}$ All bones of the body are susceptible to the disease. ${ }^{6}$ In severe cases,

Table 1. Regression equation for relationship between thickness of the angular cortex and age.

\begin{tabular}{|l|c|c|c|c|}
\hline Variant & B coefficient & T scale & P. value & Regression prediction \\
\hline Age & -0.00787 & -10.431 & 0.0001 & $\begin{array}{l}\text { Total average of cortex } \\
\text { thickness }{ }^{\star} \mathrm{R}, \mathrm{L}=\end{array}$ \\
\hline Fixed value & 5.805 & 18.973 & 0.0001 & $5.8-(0.00787 \times$ age $)$ \\
\hline
\end{tabular}

${ }^{\star} \mathrm{R}, \mathrm{L}$ : right and left

- According to regression statistical analysis the relationship between the average thickness in the mandibular angular cortex with age was significant (P.value $=0.0001)$, and with an increase in age the cortical thickness decreases significantly. 
Table 2. Regression equation for the relationship between the angular cortex and menopausal age.

\begin{tabular}{|l|c|c|c|c|}
\hline \multicolumn{1}{|c|}{ Variant } & B coefficient & T scale & P. value & Regression prediction \\
\hline $\begin{array}{l}\text { Age of } \\
\text { menopause }\end{array}$ & -0.101 & -2.953 & 0.0001 & $\begin{array}{l}\text { Total average of cortex } \\
\text { thickness } R, L=\end{array}$ \\
\hline Fixed value & 6.618 & 4.073 & 0.007 & $\begin{array}{l}6.61-(0.101 \times \text { age of } \\
\text { menopause })\end{array}$ \\
\hline
\end{tabular}

According to the regression statistical analysis the relationship of the thickness percentage for the mandibular angular cortex with menopause age is significant (P.value $=0.0001)$ and with increase in menopause age, this percentage decrease is significant.

Table 3. Regression equation for the relationship between the thickness of the angular cortex and the number of pregnancies.

\begin{tabular}{|c|c|c|c|c|}
\hline Variant & B coefficient & T scale & P. value & \begin{tabular}{c} 
Regression Prediction \\
\hline $\begin{array}{l}\text { Number of } \\
\text { pregnancies }\end{array}$
\end{tabular} \\
\hline Fixed value & -0.359 & -6.564 & 0.0001 & $\begin{array}{c}\text { Total average of cortex } \\
\text { thickness } \mathrm{R}, \mathrm{L}=\end{array}$ \\
\hline
\end{tabular}

According to the regression statistical analysis the relationship between the mandibular angular cortex and the number of pregnancies was significant ( $P$.value $=0.0001$ ). Note with each pregnancy, this percentage decreases.

Table 4. Comparison of the thickness of mandibular angular cortex according to menopause status.

\begin{tabular}{|c|c|c|c|}
\hline Menopause status & Number & Variance & The average of cortex thickness \\
\hline Menopause & 27 & 0.811 & 1.83 \\
\hline Non menopause & 72 & 1.41 & 3.13 \\
\hline
\end{tabular}

(P.value $<0.0001)$

Table 5. Comparison of the thickness of the mandibular angular cortex in relation to backache status.

\begin{tabular}{|c|c|c|c|}
\hline Backache status & Variance & Number & The average of cortex thickness \\
\hline $\begin{array}{c}\text { People with } \\
\text { backache record }\end{array}$ & 0.538 & 20 & 1.58 \\
\hline $\begin{array}{c}\text { People without } \\
\text { backache record }\end{array}$ & 1.386 & 80 & 3.08 \\
\hline
\end{tabular}

(P.value $<0.0001)$ 


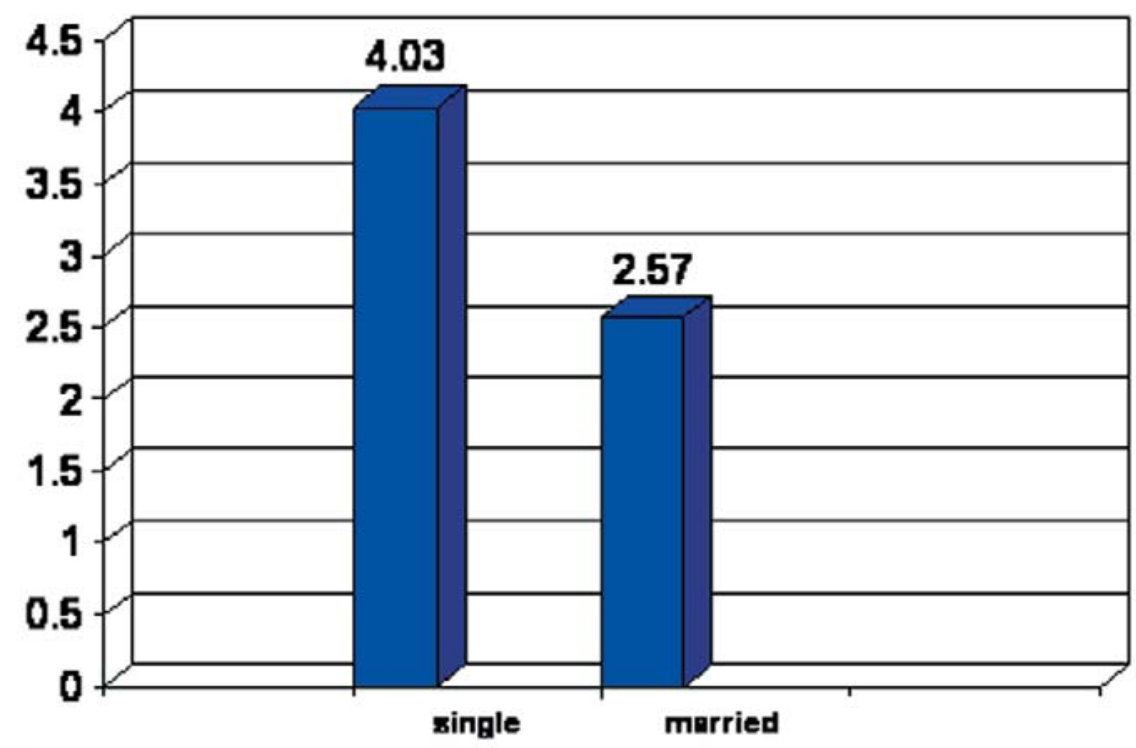

Figure 6. Comparison of the average of thickness in the mandibular angular cortex according to marital status.

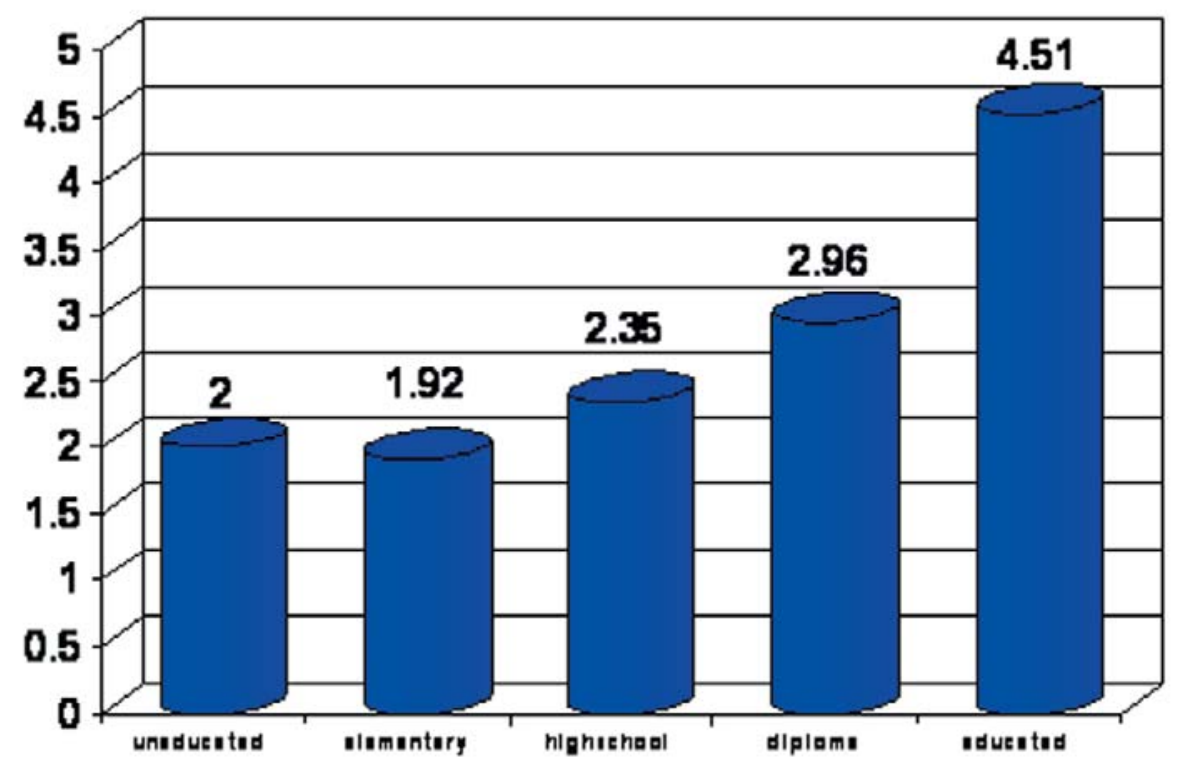

Figure 7. A comparison of the average of the mandibular angular cortex thickness in relation to educational level.

clinical symptoms are manifested as severe pains which are intensified by body movement. This pain is initiated after trauma or physical activity.

Radiographic changes of osteoporosis can be described as the reduction of bone density. Loss of the natural trabecular pattern and thinning of the bony cortex are characteristics of this disease.

In this research the thickness of the mandibular angular cortex was investigated in women who were over 20 years old because the layer of cortex which is radiopaque in mandibular angular cortex is not visible before age $15 .^{11}$

Our results show the mandibular angular cortex thickness decreases considerably after menopause. Because of the higher rate of osteoporosis in postmenopausal women, our results are similar to the results of Kribbs. ${ }^{8}$ Kribbs compared the thickness of the mandibular angular cortex in normal and osteoporotic women and found 
the thickness of the cortex in osteoporotic women is less than healthy women.

Hairi considered the effect of osteoporosis significant with regard to the reduction of residual ridge height in old edentulous patients. ${ }^{14}$ Taguchi

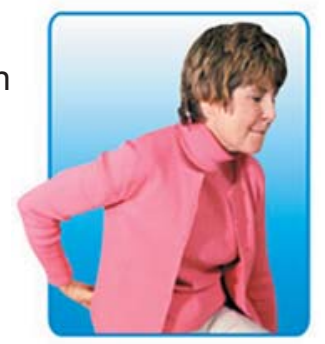
et al. ${ }^{15,16,17}$ could not find a significant relationship between the existing number of teeth and the thickness of the mandibular cortex in male patients, but found a significant relationship in females. He also found a significant relationship between the number of teeth and thoracic vertebral fractures in women between the ages of 50 70. However, in the present study the comparison between dentate and edentulous women was not useful because of a lack of sufficient edentulous subjects in the study sample.

Also, Hildebolt ${ }^{18}$ reviewed different articles about the probable relationship between osteoporosis and the resorption of jaw bones. He stated that with fast progress in the use of a common method of measurement in clinics for investigating the extent of bone loss, oral maxillofacial radiology could be very important in the early diagnosis of osteoporotic patients. Also Mohammad used panoramic radiography for diagnosing dubious cases of osteoporosis on mandibular bone. ${ }^{19}$ This was the rationale for using panoramic radiography in the present study.

Killinger pays attention to the primary diagnosis of post menopausal osteoporosis. He stated the relationship of bone density and its turn over with age and other risk factors helps to better evaluate the osteoporosis risk.

He also stated in many medical conditions the primary diagnosis is a successful key in preventing and curing osteoporosis. ${ }^{20}$

The literature presented here supports the use of oral indicators such as alveolar bone resorption, decreases in mandibular mineral density, and the thickness of mandibular cortex (visible in panoramic radiography) could be used for diagnosing osteoporotic cases. ${ }^{4,8,14}$

Klemetti and his colleages measured mineral density in mandibular cortical bone of menopausal women by qualitative computed tomography and compared it with "bone mineral density" (BMD) of the femoral neck area, lumbar vertebral, and trabecular of mandibular bone. They found the BMD of the mandibular bone cortex has a close relationship with the BMD of the femoral neck and lumbar vertebral. ${ }^{21,22}$

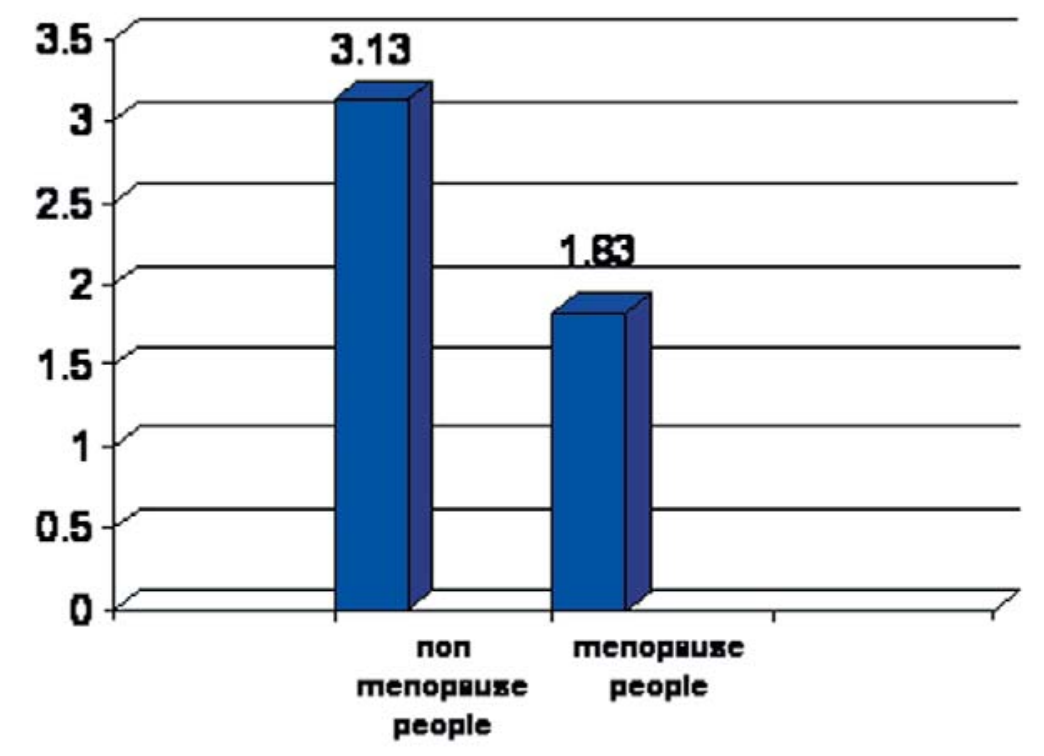

Figure 8. Comparison of the average of thickness in the mandibular angular cortex in relation to menopause status. 
This study shows with the increase in age, especially from the third decade on, a gradual decrease in the thickness of mandibular angular cortex is seen. In women in the fifth decade the decrease in thickness becomes more pronounced. This is due to a decrease in sexual hormones followed by menopause. In menopause the production of sexual hormones (estrogen) ceases. This has a double effect on the process of reducing the thickness of the mandibular cortex because these hormones protect skeletal tissues against the effects of bone reducing hormones like paratormon. ${ }^{2}$ (Figure 8 )

Also after pregnancy, a woman's body absorbs calcium from the bones to maintain its need. This will result in a decrease in the thickness of the mandibular angular cortex after every pregnancy. ${ }^{23}$

This research shows with an increase in education, the thickness of the mandibular angular cortex increases. Because educated people have more knowledge and information they are more aware of a favorable diet to minimize the process of bone reduction.

The comparison between the thickness of the mandibular angular cortex in women with a history of backaches revealed that women with backaches have less thickness. Since a primary reason for chronic backaches in the elderly is osteoporosis, the lack of cortical thickness could be a warning sign for osteoporosis in these women. ${ }^{1}$
Osteoporosis has a direct relationship with malnutrition; the low consumption of calcium in life can cause the maximum reduction of bone mass. This could result in an increased risk of bone fracture. Continuous production of bone matrix by osteoblasts requires that sufficient protein be absorbed from the intestines. A low protein diet, vitamin $\mathrm{C}$ deficiency, and a high level of vitamin A can cause osteoporosis. $^{1,5}$

There was a significant relationship between a woman's job and the thickness of her cortical bone. Women who have a job outside the home had a greater thickness of the mandibular angular cortical bone in comparison with housewives. This could be attributed to increased body movement associated with their job than a housewife who might be more sedentary. Inactivity causes quick resorption of bone which is related to an increase in resorption and a decrease of new bone production. Exercise or body movement can help minimize the resorption of bone in menopausal women.

\section{Conclusion}

Finally, if we can identify the osteoporotic process using a basic panoramic radiography measurement technique, then it is possible to intercept the progress of the disease through early warning and treatment.

From the results of this study, it can be concluded the thickness of the mandibular angular cortex can be used as an index for bone resorption. 


\section{References}

1. Wood, N.K. \& Goaz, P.W. Differential diagnosis of oral and maxillofacial lesion. 5th ed. New York, Mosby, 1997, chap: 23, P: 397-9.

2. Langlais, R. \& Langland, O.E. Diagaostic imaging of the jaws. 5th ed. London, Williams \& Wilkins, 1995, chap: 16, P: 449-73.

3. White, S.C. \& Pharoah, M.J. Oral radiology principles and interpretation. 4th Ed. NewYork, Mosby. 2000, chap: 23, P: 472-490.

4. Bras J, van Ooij CP, Abraham-Inpijn L, et. al. Radiographic interpretation of the mandibular angular cortex: A diagnostic tool in metabolic bone loss. Part I. Normal state. Oral Surg Oral Med Oral Pathol. 1982 May;53(5):541-5. No abstract available.

5. Stein, J. Internal Medicine, 4th ed. London St. Louis, Mosby, 19994, chap:3, P:100-23.

6. Fauci, A., Braum wald, E., Randolph, T. et al. Harrisons principles of internal medicine. 14th ed. New York Mc Grawwall, 1993, chap: 335, P: 2247-53.

7. Sutton, D. Text book of radiology and medical imaging. VOI 1. 5th ed. London, Churchill-Lioingstone, 1993, chap: 4, P: 98-109.

8. Kribbs, PJ. Comparison of mandibular bone in normal and osteoporotic women. J Prosthet Dent. 1990 Feb;63(2):218-22.

9. Jeffcoat MK, Chesnut $\mathrm{CH}$ 3rd. Systemic osteoporosis and oral bone loss: evidence shows increased risk factors. J Am Dent Assoc. 1993 Nov;124(11):49-56. Review.

10. Birkenfeld L, Yemini M, Kase NG, et. al. Menopause-related oral alveolar bone resorption: a review of relatively unexplored consequences of estrogen deficiency. Menopause. 1999 Summer;6(2):12933. Review.

11. Benson BW, Prihoda TJ, Glass BJ. Variations in adult cortical bone mass as measured by a panoramic mandibular index. Oral Surg Oral Med Oral Pathol. 1991 Mar;71(3):349-56.

12. Devlin $\mathrm{H}$, Horner $\mathrm{K}$. Measurement of mandibular bone mineral content using the dental panoramic tomogram. J Dent. 1991 Apr;19(2):116-20.

13. Kribbs, PJ. Two-year changes in mandibular bone mass in an osteoporotic population. J Prosthet Dent. 1992 May;67(5):653-5.

14. Hirai T, Ishijima T, Hashikawa $Y$, et. al. Osteoporosis and reduction of residual ridge in edentulous patients. J Prosthet Dent. 1993 Jan;69(1):49-56.

15. Taguchi A, Tanimoto K, Suei Y, et. al. Tooth loss and mandibular osteopenia. Oral Surg Oral Med Oral Pathol Oral Radiol Endod. 1995 Jan;79(1):127-32.

16. Taguchi A, Tanimoto K, Suei $Y$, et. al. Oral signs as indicators of possible osteoporosis in elderly women. Oral Surg Oral Med Oral Pathol Oral Radiol Endod. 1995 Nov;80(5):612-6.

17. Taguchi A, Suei $Y$, Ohtsuka M, et. al. Relationship between bone mineral density and tooth loss in elderly Japanese women. Dentomaxillofac Radiol. 1999 Jul;28(4):219-23.

18. Hildebolt CF. Osteoporosis and oral bone loss. Dentomaxillofac Radiol. 1997 Jan;26(1):3-15. Review.

19. Mohammad AR, Alder M, McNally MA. A pilot study of panoramic film density at selected sites in the mandible to predict osteoporosis. Int J Prosthodont. 1996 May-Jun;9(3):290-4.

20. Killinger Z. [Early diagnosis of postmenopausal osteoporosis] Bratisl Lek Listy. 2000;101(3):179-80. Slovak.

21. Klemetti E, Kolmakov S, Heiskanen $P$, et. al . Panoramic mandibular index and bone mineral densities in postmenopausal women. Oral Surg Oral Med Oral Pathol. 1993 Jun;75(6):774-9.

22. Klemetti E, Vainio P, Lassila V, et. al. Cortical bone mineral density in the mandible and osteoporosis status in postmenopausal women. Scand J Dent Res. 1993 Aug;101(4):219-23.

23. Williams, J.W., Leveno, K.J., Hauth, J.C. et al, Williams Obstetrics, 21st ed. New York, McGraw- Hill, 1997, chap:10, P: 236. 
About the Authors

\section{Fatemeh Ezoddini Ardakani, DDS, MS}

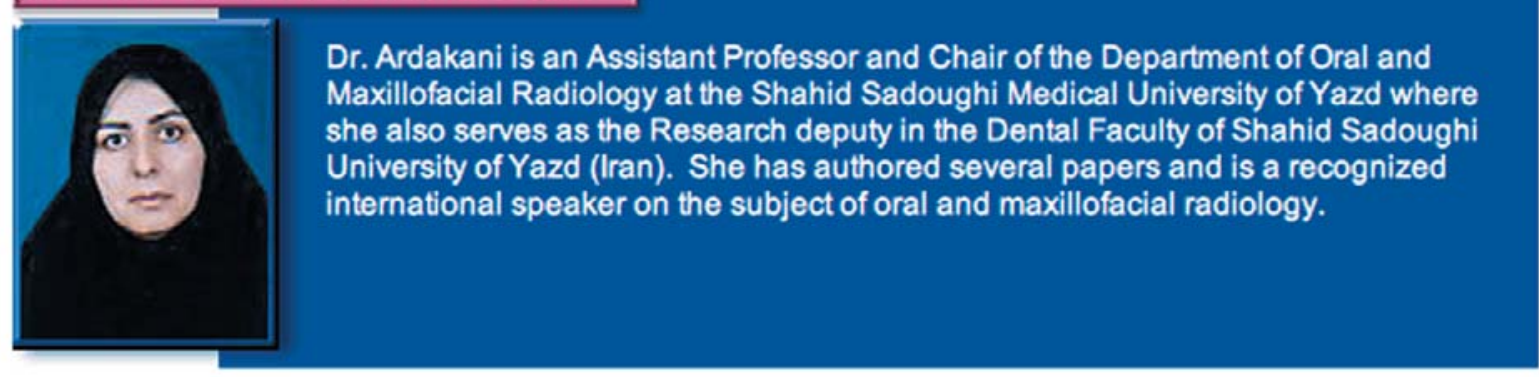

\section{Nasim Niafar, DDS}

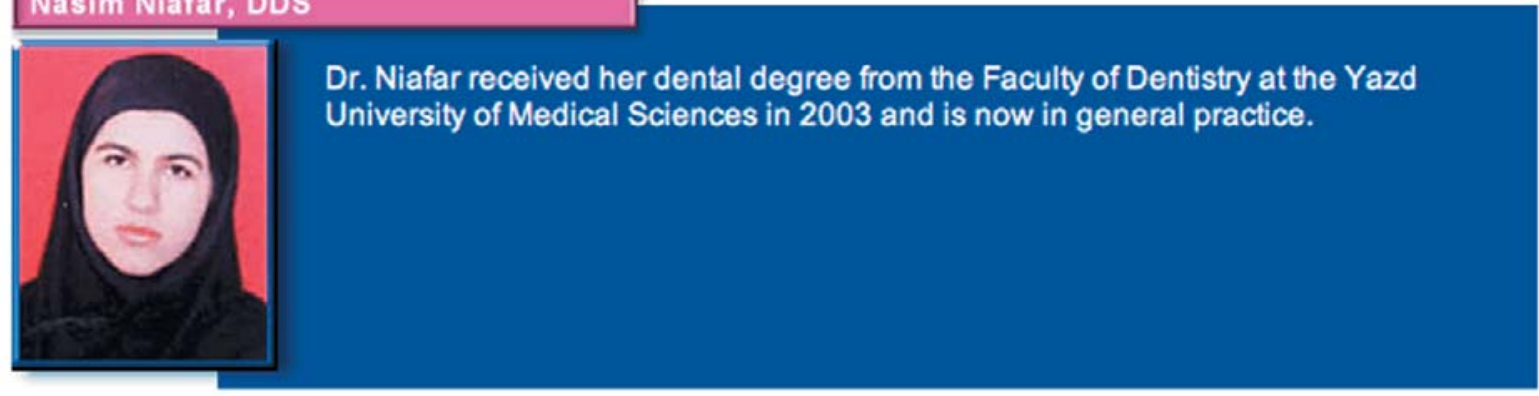

